\title{
THE EQUIVALENCE BETWEEN MANN AND IMPLICIT MANN ITERATIONS
}

\author{
B. E. RHOADES AND ŞTEFAN M. ŞOLTUZ
}

Abstract. We shall prove the equivalence bewteen the convergences of Mann and implicit Mann iterations dealing with various classes of non-Lipschitzian operators.

Mathematics subject classification (2000): 47H10.

Key words and phrases: Mann iteration, implicit Mann iteration, uniformly pseudocontractive map, uniformly accretive map.

\section{REFERENCES}

[1] S. S. ChAng, Y. J. CHO, B. S. LeE, J. S. Jung, S. M. KANG, Iterative approximations of fixed points and solutions for strongly accretive and strongly pseudo-contractive mappings in Banach spaces, J. Math. Anal. Appl. 224 (1998), 149-165.

[2] S. IsHIKAWA, Fixed points by a new iteration method, Proc. Amer. Math. Soc. 44 (1974), 147-150.

[3] W. R. ManN, Mean value methods in iteration, Proc. Amer. Math. Soc. 4 (1953), 506-510.

[4] B. E. RHOADES AND ŞTEFAN M. ŞOLTUZ, On the equivalence of Mann and Ishikawa iteration methods, Int. J. Math. Math. Sci. 2003 (2003), 451-459.

[5] B. E. RHOADES AND ŞTEFAN M. ŞOLTUZ, The equivalence of Mann iteration and Ishikawa iteration for non-Lipschitzian operators, Int. J. Math. Math. Sci. textbf2003 (2003), 2645-2652.

[6] B. E. RHOADES AND ŞTEFAN M. ŞOLTUZ, The equivalence between the convergences of Ishikawa and Mann iterations for asymptotically pseudocontractive mapas, J. Math. Anal. Appl. 283 (2003), 681-688.

[7] B. E. RHOADES AND ŞTEFAN M. ŞOLTUZ, The equivalence of Mann and Ishikawa iteration for a Lipschitzian psi-uniformly pseudocontractive and psi-uniformly accretive maps, Tamkang J. Math. 35 (2004), 235-245.

[8] B. E. RHOADES AND ŞTEFAN M. ŞOLTUZ, The equivalence between the convergences of Ishikawa and Mann iterations for asymptotically nonexpansive in the intermediate sense and strongly successively pseudocontractive maps, J. Math. Anal. Appl. 289 (2004), 266-278.

[9] B. E. RhOAdES AND ŞTEFAN M. ŞOLtUZ, The equivalence of Mann and Ishikawa iteration for $\psi$ - uniformly pseudocontractive or $\psi$-uniformly accretive maps, Int. J. Math. Math. Sci. 2004:46, 2443-2452.

[10] B. E. RhOADES AND ŞTEFAN M. ŞOLtUZ, The convergence of an implicit mean value iteration, Int. J. Math. Math. Sci. 2006 ID 68369.

[11] ŞTEFAn M. ŞoltuZ, The backward Mann iteration, Octogon Math. Mag. 9 (2001), 797-800. 